\title{
Article \\ Cardiac Output Evaluation on Septic Shock Patients: Comparison between Calibrated and Uncalibrated Devices during Vasopressor Therapy
}

\author{
Paolo Persona ${ }^{1, *} \mathbb{\infty}$, Ilaria Valeri ${ }^{2} \mathbb{D}$, Elisabetta Saraceni ${ }^{3}$, Alessandro De Cassai ${ }^{1}$, Fabrizia Calabrese ${ }^{1}(\mathbb{D}$ \\ and Paolo Navalesi 2 (D) \\ 1 UOC Institute of Anaesthesia and Intensive Care Unit, University Hospital of Padua, 35121 Padua, Italy; \\ alessandro.decassai@gmail.com (A.D.C.); fabrycal@hotmail.com (F.C.) \\ 2 UOC Institute of Anaesthesia and Intensive Care Unit, Department of Medicine-DIMED, University of Padua, \\ 35121 Padua, Italy; ilaria.valeri.90@gmail.com (I.V.); pnavalesi@gmail.com (P.N.) \\ 3 Clinical Department of Anaesthesiology and Intensive Care Medicine, SS. Annunziata Hospital, \\ 66100 Chieti, Italy; betta.saraceni@gmail.com \\ * Correspondence: ppersona75@gmail.com; Tel.: +39-049-821-3090
}

check for updates

Citation: Persona, P.; Valeri, I.; Saraceni, E.; De Cassai, A.; Calabrese,

F.; Navalesi, P. Cardiac Output

Evaluation on Septic Shock Patients:

Comparison between Calibrated and Uncalibrated Devices during Vasopressor Therapy. J. Clin. Med. 2021, 10, 213. https://doi.org/ $10.3390 /$ jcm10020213

Received: 10 December 2020 Accepted: 5 January 2021 Published: 9 January 2021

Publisher's Note: MDPI stays neutral with regard to jurisdictional clai$\mathrm{ms}$ in published maps and institutional affiliations.

Copyright: (C) 2021 by the authors. Licensee MDPI, Basel, Switzerland. This article is an open access article distributed under the terms and conditions of the Creative Commons Attribution (CC BY) license (https:// creativecommons.org/licenses/by/ $4.0 /)$.

\begin{abstract}
There are no reliable, non-invasive methods to accurately measure cardiac output (CO) in septic patients. MostCare (Vytech Health ${ }^{\mathrm{TM}}$, Vygon, Padova, Italy), is a beat-to-beat, self calibrated method for $\mathrm{CO}$ measurement based on continuous analysis of reflected arterial pressure waveforms. We enrolled 40 patients that were suffering from septic shock and requiring norepinephrine infusion to target blood pressure in order to to evaluate the level of agreement between a calibrated transpulmonary thermodilution device (PiCCO System, Pulsion Medical Systems, Feldkirchen, Germany) and the MostCare system in detecting and tracking changes in $\mathrm{CO}$ measurements related to norepinephrine reduction in septic shock patients,. PiCCO was connected to a $5 \mathrm{Fr}$ femoral artery catheter and to a central venous catheter. System calibration was performed with $15 \mathrm{~mL}$ of cold saline injection over about $3 \mathrm{~s}$. The MostCare device was connected to the artery catheter to analyze the arterial waveform. Before reducing norepinephrine infusion, the PiCCO system was calibrated, the MostCare waveform was optimized, and the values of the complete hemodynamic profile were recorded (T1). Norepinephrine infusion was then reduced by $0.03 \mathrm{mcg} / \mathrm{Kg} / \mathrm{min}$. After $30 \mathrm{~min}$, a new calibration of PiCCO system and a new record on both monitors were performed (T2). Static measurements agreements were assessed using the Bland-Altman test, while trending ability was investigated using polar plot analysis. If volume expansion occurred, then related data were separately analyzed. At T1 mean the CO was 5.38 (SD 0.60) L/min, the mean difference was $0.176 \mathrm{~L} / \mathrm{min}$, the limits of agreement (LoA) was +1.39 and $-1.04 \mathrm{~L} / \mathrm{min}$, and the percentage error (PE) was $22.6 \%$; at $\mathrm{T} 2$ the mean CO was $5.44(\mathrm{SD} 0.73) \mathrm{L} / \mathrm{min}$, the mean difference was $0.053 \mathrm{~L} / \mathrm{min}$, the LoA was +1.51 and -1.40 , and the PE was $27 \%$. After considering the volume expansion between $\mathrm{T} 1$ and $\mathrm{T} 2$, the mean $\mathrm{CO}$ at $\mathrm{T} 1$ was $5.39 \mathrm{~L} / \mathrm{min}$ (SD 0.47), the LoA was +1.09 and $-0.78 \mathrm{~L} / \mathrm{min}$, and the percentage error (PE) was $17 \%$; at $\mathrm{T} 2$ the mean CO was $5.35 \mathrm{~L} / \mathrm{min}$ (SD 0.81), the LoA was +1.73 and $-1.52 \mathrm{~L} / \mathrm{min}$, and the PE was $30 \%$. The polar plot diagram seems to confirm the trending ability of MostCare system versus the reference method. In septic patients, when the arterial waveform is accurate, MostCare and PiCCO transpulmonary thermodilution exhibit good agreement even after the reduction of norepinephrine and changes in vascular tone or volume expansion. MostCare could be a rapid to set, reliable, and useful tool to monitor hemodynamic variations in septic patients in emergency contexts where thermodilution methods or other advanced systems are not easily available.
\end{abstract}

Keywords: hemodynamic monitoring; septic shock; MostCare; transpulmonary thermodilution 


\section{Introduction}

There are no reliable, non-invasive, easy, and rapid setup methods to accurately measure cardiac output (CO) in septic patients in an emergency setting. The invasiveness and the potentially negative impact on outcome [1-3] of the reference method of $\mathrm{CO}$ assessment, the pulmonary artery catheter (PAC), has encouraged the development of new devices. Nevertheless, some concerns have been raised about the accuracy and precision of $\mathrm{CO}$ measurements being performed by different hemodynamic monitoring systems.

As $\mathrm{CO}$, together with the arterial impedance and heart rate, is the main determinant of arterial pressure, many algorithms have been developed in order to calculate $\mathrm{CO}$ based on pulse contour analysis of the arterial pressure waveform [4].

Many pulse contour methods are now available for clinical purposes, and most of them need to be calibrated by using an indicator (ice cold saline or lithium); others analyze the geometric variations of the arterial waveform in comparison to an internal database $[5,6]$.

However, especially in septic patients, the main issue of pulse contour methods concerns the lack of measurement of the arterial system impedance [7]. Arterial impedance and elastance in fact often change in sepsis, due to the extreme vasodilation and the extensive use of norepinephrine and vasopressin to maintain vascular tone and mean pressure. For this reason, the re-calibration of transpulmonary thermodilution based devices is considered to be essential to get reliable data on cardiac performance after vasopressor modification [8-11].

If properly managed, transpulmonary thermodilution methods also appear to not be inferior to PAC for also measuring CO in septic patients [12-14].

MostCare (Vytech Health ${ }^{\mathrm{TM}}$, Vygon, Padova, Italy) is a beat-to-beat, self-calibrated method for CO measurement, based on continuous analysis of reflected waves recorded on pulse contour at 1000 points/s [15]. Based on Pressure Recording Analytical Method (PRAM), it identifies the points of instability distributed along the systolic and diastolic phases of the arterial waveform; calculations take into account the forward (from the heart) and the backward (from peripheral vessels) waves. The continuous evaluation of cardiac output (CCO) may give a real time assessment of heart performance related to modifications of arterial preload and afterload.

MostCare's performance on the septic population has not been clarified yet, due to the discordant results of the few available studies $[16,17]$.

The aim of our work was to evaluate the level of agreement between a calibrated transpulmonary thermodilution device (PiCCO System, Pulsion Medical Systems, Feldkirchen, Germany), and the MostCare system in detecting and tracking changes in CCO measurements related to norepinephrine reduction in septic shock patients.

\section{Methods}

We performed a single center observational clinical study.

After local ethic committee approval (Ethical Board protocol $n^{\circ} 26658$ ), we considered 50 consecutive patients admitted to our 19 bed ICU for enrollment with the following inclusion criteria: (1) diagnosis of septic shock; (2) norepinephrine infusion; (3) a previous clinical decision to use the PiCCO system for hemodynamic monitoring; (4) age >18 years. Exclusion criteria were: (1) any clinical condition that could interfere with the reliability of the reference method (valvular regurgitations, post-aneurismatic endoleaks, lung resections, etc.) [18]; (2) over or under damped arterial waveform artefacts despite the use of internal or external filters (the MostCare monitor erases some harmonica as part of arterial waveforms that present a too steep ascending line in the systolic phase).

Written informed consent or delayed consent was obtained from each patient or legal surrogate according to the Local Ethics Committee dispositions. This manuscript adheres to the applicable EQUATOR guidelines.

Septic shock was diagnosed according to the criteria reported by Rhodes et al. [19].

Before inclusion in the study, a trained staff physician performed a transthoracic echocardiography; if major valvular defects, intracardiac shunts, or other conditions that 
could afflict the accuracy of transpulmonary thermodilution method were diagnosed, then the patient was excluded from the study [18]. PiCCO was connected to a $5 \mathrm{Fr}$ femoral artery catheter (Pulsiocath PV2015L20, Pulsion Medical Systems), and to a central venous catheter with the tip at the cavoatrial junction. System calibration was performed with $15 \mathrm{~mL}$ of iced saline injection (temperature $<8^{\circ} \mathrm{C}$ ) for about $3 \mathrm{~s}$. The reproducibility of the measurement was tested by performing 3 subsequent calibrations. If a difference greater than $20 \%$ between each CO-thermodilution measurement occurred, then a new calibration series was performed and considered.

The MostCare device was connected to the patient monitor to analyze the arterial waveform. MostCare estimates stroke volume (SV) based on the formula SV $=\mathrm{A} / \mathrm{Z}$, where $\mathrm{A}$ is the systolic part of the curve and $\mathrm{Z}$ is the impedance of the system; $\mathrm{Z}$ is calculated as $\mathrm{P} / \mathrm{t} \times \mathrm{K}$, where $\mathrm{P}$ is instant pressure and $\mathrm{t}$ is time, while considering a beat to beat analysis of the whole cardiac cycle and the reflected waves from the arterial system. The reflected waves cause instability points with different velocities on the pulse contour detected by analysis at 1000 points/sec by MostCare. $\mathrm{K}$ is calculated as the ratio between expected and measured mean blood pressures, assuming that the numerator is constant according to Guyton studies [20,21].

The fast-flush test was performed and, if arterial resonance occurred, the signal was optimized with specific devices [22] or using MostCare filters [23]. If the signal, despite the efforts to clear it, was over or under damped based on the already described technique [24], then the patient was excluded from the study. A mean of $10 \mathrm{~s}$ consecutive MostCare CCO values were considered for comparison.

Before any clinical decision to reduce norepinephrine, in accordance with our internal protocol, the PiCCO system was calibrated [25], the MostCare waveforms were optimized, and the values of the complete hemodynamic profile were recorded (T1). Norepinephrine infusion was then reduced by $0.03 \mathrm{mcg} / \mathrm{Kg} / \mathrm{min}$. After $30 \mathrm{~min}$, a new calibration of PiCCO system and a new record on both monitors were performed (T2). Data from PiCCO and MostCare during the norepinephrine de-escalation were recorded and stored for off-line analysis.

Between T1 and T2 measurements, clinicians were free to perform volume expansion with $500 \mathrm{~mL}$ of crystalloids to maintain mean arterial pressure (MAP).

\section{Statistical Analysis}

We planned a study of a continuous response variable using matched pairs of study values. Prior data indicate that the difference in the response of matched pairs is normally distributed with a standard deviation of 1 . If the true difference in the mean response of matched pairs was 0.55 , then we needed to study 37 subjects (paired evaluations) to be able to reject the null hypothesis that this response difference is zero with a probability (power) of 0.9. The Type I error probability associated with this test of this null hypothesis is 0.05 .

To assess whether the values were normally distributed, we performed the ShapiroWilk test. Correlations were found using the Pearson product moment coefficient. Static measurements agreements were assessed using the Bland-Altman test [26], considering the limits of agreement (LoA), and the percentage error (PE), to test the precision of the measurement. PE was calculated as the ratio between limits of agreement of the bias and the mean CO of the two systems. According to the literature, a PE of less than $30 \%$ is considered to be acceptable for clinical purposes [27]. Trending ability was investigated using polar plot analysis. The polar plot analysis is widely described elsewhere [28]; briefly, the agreement is shown by angle $\theta$ made by $\Delta \mathrm{CO}$ vector with the line of identity $(\mathrm{y}=\mathrm{x})$ against the change in the $\mathrm{CO}$ as the radian (distance of data point from center of polar plot). $\Delta \mathrm{CO}$ lying between $30^{\circ}$ radial sector limits, excluding data within $10 \%$ of the $\mathrm{CO}$, should identify a good trending ability.

\section{Results}

We considered 50 patients for enrolment. Six patients were excluded due to an inappropriate arterial waveform signal based on an amplitude ratio and natural frequency 
calculation, despite the efforts to correct it; four patients were excluded because of severe mitral regurgitation (3) and tricuspidal regurgitation (1). Demographic data, origins of septic shock, and severity scores of the 40 included patients are shown in Table 1.

Table 1. Patients characteristics. Data are expressed as percentage and mean \pm standard deviation.

\begin{tabular}{cc}
\hline Patients' Characteristics & Values \\
\hline Age (years) & $64 \pm 12$ \\
\hline Gender $(\mathrm{M} / \mathrm{F})$ & $76 \pm 12$ \\
\hline Weight $(\mathrm{Kg})$ & $174 \pm 15$ \\
\hline Height $(\mathrm{cm})$ & $1.83 \pm 0.23$ \\
\hline Body surface area $\left(\mathrm{m}^{2}\right)$ & $42 \pm 9.3$ \\
\hline SAPS II & $18(45 \%)$ \\
\hline Origin of septic shock & $10(25 \%)$ \\
\hline abdominal & $4(10 \%)$ \\
\hline pulmonary & $4(10 \%)$ \\
\hline bacteremic & $1(2.5 \%)$ \\
\hline soft tissues & $1(2.5 \%)$ \\
\hline cerebral & $2(5 \%)$ \\
\hline ob/gyn &
\end{tabular}

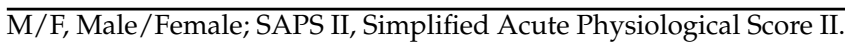

The mean heart rate at T1 was $83 \mathrm{bpm}$ (SD 9.24) and at T2 was $81 \mathrm{bpm}$ (SD 7.18). The mean MAP at T1 was 76.15 (SD 3.04) $\mathrm{mmHg}$, after $15 \mathrm{~min}$ it was 67.6 (SD 3.01) $\mathrm{mmHg}$ and at T2 it was 74.5 (SD 3.34) mmHg; variations in MAP are depicted in Figure 1.

Fifteen patients received $500 \mathrm{~mL}$ of crystalloids between $\mathrm{T} 1$ and $\mathrm{T} 2$.

A total of $160 \mathrm{CO}$ measurements were collected. The Pearson product moment correlation between PiCCO and MostCare at T1 and T2 was 0.9 and 0.83, respectively. To investigate if the variation of norepinephrine afflicted the accuracy and precision of MostCare, we performed a separate Bland-Altman analysis at T1 and T2. At T1 the mean $\mathrm{CO}$ was 5.38 (SD 0.60) $\mathrm{L} / \mathrm{min}$, the mean difference was $0.176 \mathrm{~L} / \mathrm{min}$, the LoA was +1.39 and $-1.04 \mathrm{~L} / \mathrm{min}$, and the PE was $22.6 \%$; at $\mathrm{T} 2$ the mean $\mathrm{CO}$ was 5.44 (SD 0.73) $\mathrm{L} / \mathrm{min}$, the mean difference was $0.053 \mathrm{~L} / \mathrm{min}$, the LoA was +1.51 and -1.40 , and the PE was $27 \%$. Agreement between cardiac output measured by MostCare (MCO) and cardiac output measured by PiCCO transpulmonary thermodilution (PCO) at the baseline (T1) and $30 \mathrm{~min}$ after norepinephrine reduction (T2) is shown in Figure 2.

After considering patients who received volume expansion between $\mathrm{T} 1$ and $\mathrm{T} 2$, the mean $\mathrm{CO}$ at $\mathrm{T} 1$ was $5.39 \mathrm{~L} / \mathrm{min}$ (SD 0.47), the $\mathrm{LoA}$ was +1.09 and $-0.78 \mathrm{~L} / \mathrm{min}$, and the PE was $17 \%$; at T2 the mean CO was $5.35 \mathrm{~L} / \mathrm{min}$ (SD 0.81), the LoA was +1.73 and $-1.52 \mathrm{~L} / \mathrm{min}$, and the PE was $30 \%$.

The trending ability of MostCare of overall patients is shown by data points dispersion on polar plot analysis (Figure 3): 29 data points (difference in CO between T1 and T2), were inside $10 \%$ of $C O$ variation, indicating a substantial correspondence between the two values. Among the remaining 11 data points, the polar concordance was $82 \%$ (data between $30^{\circ}$ angles). 


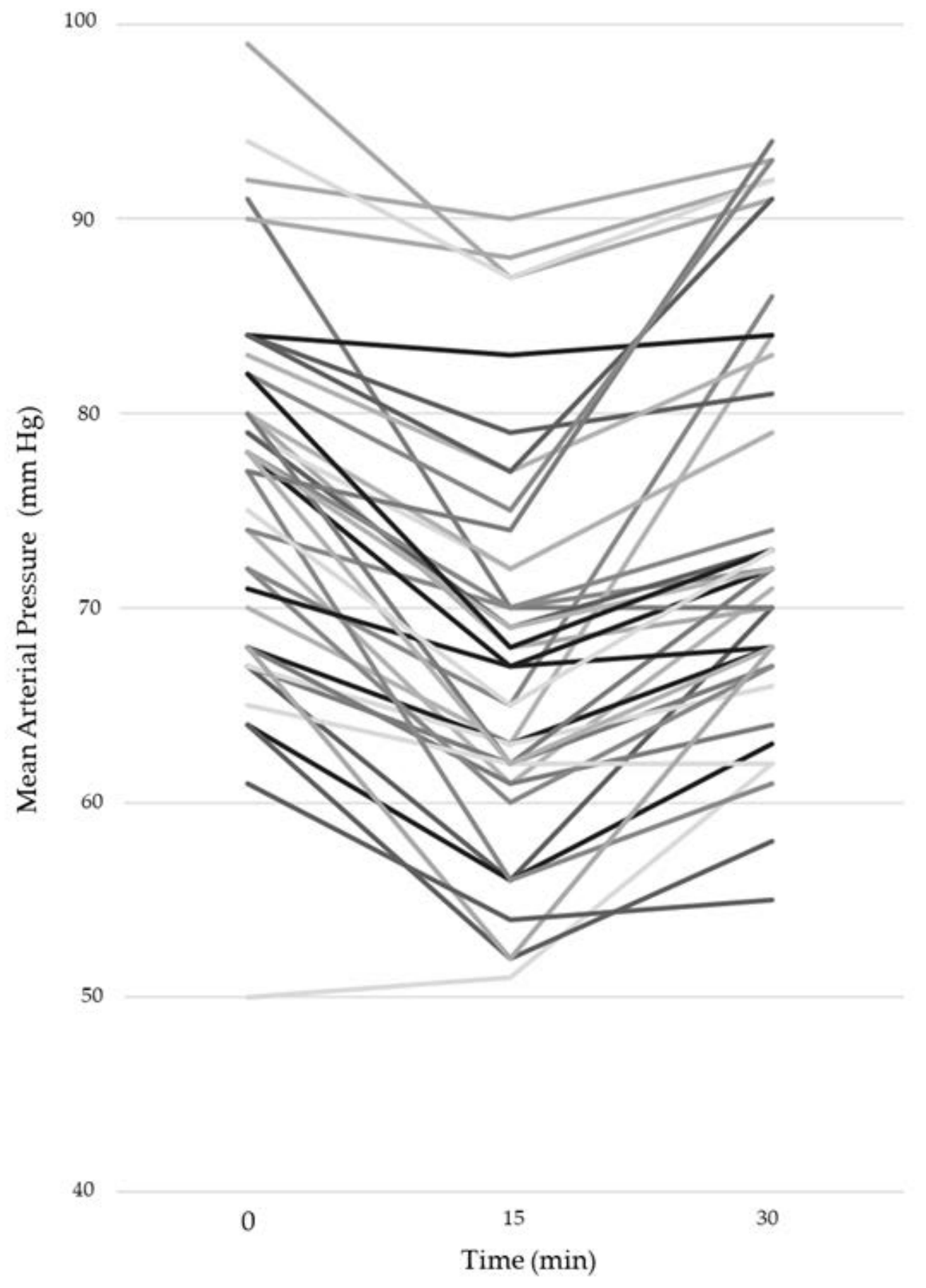

Figure 1. Mean Arterial Pressure changes at baseline, after $15 \mathrm{~min}$ and after $30 \mathrm{~min}$ from norepinephrine infusion reduction. 
Panel A

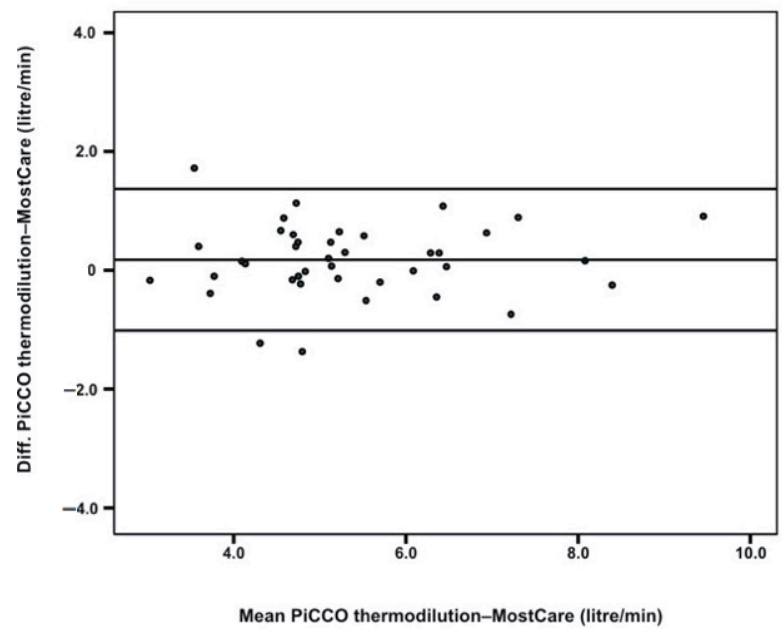

Panel B

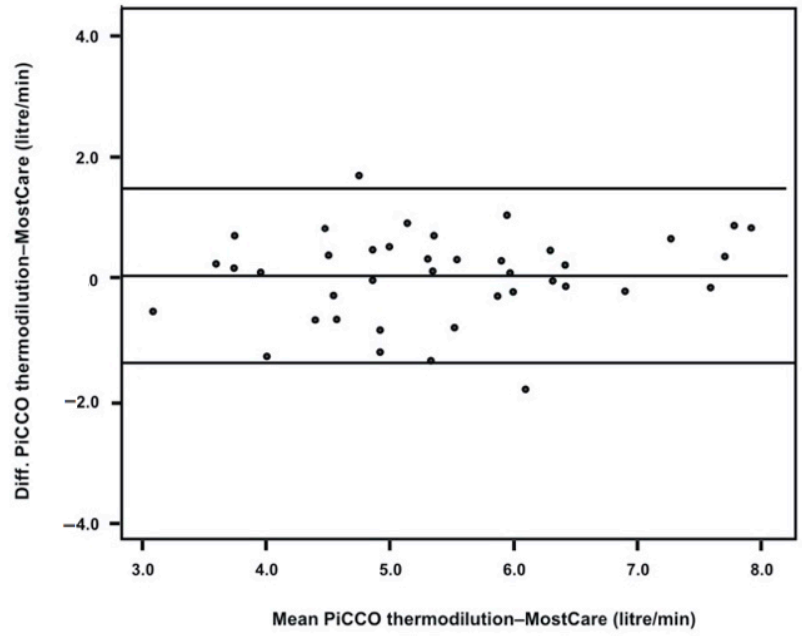

Figure 2. (Panel A) Bland-Altman plot at T1; the horizontal lines on the scatterplot represent the bias and the limits of agreement (mean bias \pm 2 Standard Deviations). (Panel B) Bland-Altman plot at T2; the horizontal lines on the scatterplot represent the bias and the limits of agreement (mean bias \pm 2 Standard Deviations).

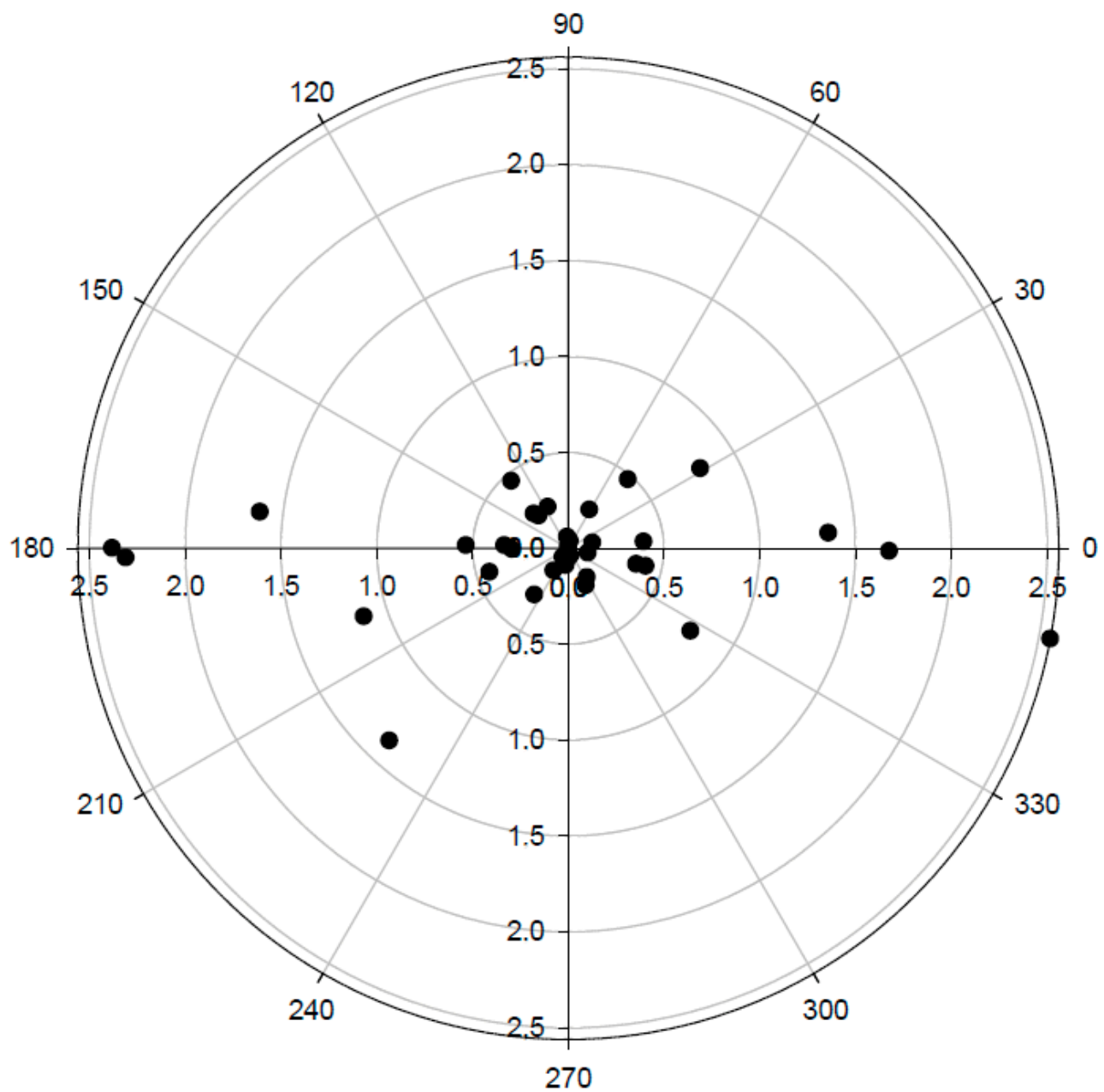

Figure 3. Polar plot showing the trending ability. This was obtained by converting $\mathrm{CO}$ variation obtained between $\mathrm{T} 1$ and T2 from PiCCO System (X-axis) and MstCare system (Y-axis). Radial sector limits, excluding data within 10\% of CO variation, identify a good trending ability. 


\section{Discussion}

In clinical settings where hemodynamic monitoring could be useful but invasive tools are not immediately and easily available, there is a lack of knowledge about the reliability of less invasive and rapid setup methods. The purpose of our study was to evaluate the level of agreement between a calibrated transpulmonary thermodilution device (PiCCO System) and an uncalibrated one (MostCare) in detecting and tracking changes in CO measurements during "dynamic" clinical conditions related to vasopressor de-escalation in septic shock patients. MostCare uses a patented algorithm to estimate CO, but some concerns have been raised about its ability to self-calibrate in clinical situations where arterial tone rapidly changes [17].

The PiCCO system is an invasive tool which has been validated in animal models and in humans under several clinical conditions $[8,29]$. Its numerous advantages have already been highlighted [18]. Transpulmonary thermodilution CO assessment is based on calculations that were verified under stable setting and sinus rhythm conditions. Despite criticism of the use of PiCCO in unstable clinical conditions [30,31], many authors [8,32,33] found good agreement with the reference method, thereby also confirming its good performance in hemodynamically unstable and septic shock patients $[12,13]$.

Notably, PiCCO needs a dedicated arterial catheter, a central venous line, and a calibration after any hemodynamic perturbation, such as vasopressor variations or fluid challenges [25]; its continuous cardiac output measurement, based on pulse contour analysis, better fits with transpulmonary thermodilution if it is re-calibrated every hour [11]. All these characteristics make this device difficult to use in clinical settings like emergency wards.

The MostCare system has been evaluated and validated in different clinical settings [23, 34-36].

However, the literature provides only a few reports of its use in septic patients or during hemodynamic instability, with controversial results. Franchi et al. [16] showed a good correlation between MostCare and PAC on tracking changes in arterial tone by increasing and decreasing norepinephrine dosage; variations were targeted on a predefined value of arterial pressure and in selected hemodynamic stable patients. In contrast, Gopal et al. [17] showed a poor correlation with PAC in septic patients, but neither data about arterial waveform artefacts nor ultrasound heart assessments [37] were considered.

As observed by other authors [38], the change in arterial load seems to be the main determinant of differences between central and peripheral CO assessments, and this is a typical feature of septic patients. In our population, the arterial elastance and net compliance were altered by sepsis and vasopressor modifications. In this view, a hemodynamic monitoring system should be able not only to record a static value in $\mathrm{CO}$, but also to track any variation in the hemodynamic setting. Some authors suggested that a less accurate measurement may be acceptable if the trend analysis is reliable [39]. In our study the norepinephrine dosage reduction was constant $(0.03 \mathrm{mcg} / \mathrm{Kg} / \mathrm{min})$, as occurs in our clinical practice. This variation altered the equilibrium of the cardiovascular system for all the patients (Figure 1), and clinicians were free to perform a fluid challenge if needed. None of the patients needed to get a re-increase in the norepinephrine dosage. Unfortunately, the $\mathrm{CO}$ values at $\mathrm{T} 1$ and $\mathrm{T} 2$ were similar for the majority of our patients, thereby limiting the power of tracking analysis. Anyway, the polar plot diagram seems to confirm the trending ability of the MostCare system versus the reference method, but this has to be confirmed by larger studies. The large number of dots inside the exclusion zone represents the statistical noise due to the high level of random variability.

In our group of patients, when separately analyzed at $\mathrm{T} 1$ and $\mathrm{T} 2$, the $\mathrm{CO}$ values measured by the two systems showed acceptable LoA and PE outcomes. In the subgroup that received both volume expansion and norepinephrine reduction, MostCare showed a good agreement with the reference method, if compared with different monitoring systems [40]. The opportunity to get a rapid assessment and continuous monitoring of CO in a septic patient could be very useful for guiding a goal-directed approach from the early phase of presentation, in order to manage hemodynamic instability and optimize treatment. 
Moreover, we considered patients with septic shock originating from different sites, as the source of infection is often still unknown at presentation in emergency departments.

We only excluded patients affected by conditions that could limit the reliability of the reference method [18] and those who did not show an optimal arterial waveform due to over/under-damped signal. The quality of the arterial waveform is of paramount importance, particularly when considering the MostCare system, as it analyzes arterial waveform at 1000 points/s. Romagnoli et al. [23] found 30.7\% of patients with an under-damped arterial signal in vascular and cardiac surgery. An under-damped signal can lead to a significant overestimation of the $\mathrm{CO}$ when measured by the MostCare system, which does not seem to be an independent operator or a 'plug and play' monitor. The optimization of the waveform signal to avoid resonance artifacts is time consuming and is based on mathematical calculations [24]. In our study, the system was not reliable a priori in $12 \%$ of our patients, due to arterial artifacts. In fact in 6 patients, despite the efforts to correct the quality of output waveform signal, an under-damped arterial waveform was recorded.

This study presents some caveats: the first involves the reference method. Transpulmonary thermodilution, despite extensive papers confirming its reliability, has several limitations and the differences between PCO and MCO could hypothetically be partly related to PiCCO's performance. The second is that we performed transthoracic echocardiography rather than transesophageal echocardiography to exclude conditions that could afflict the accuracy of the reference method; transthoracic echocardiography has notably been proposed as a reference method in several studies assessing $\mathrm{CO}[34,37]$.

\section{Conclusions}

In septic patients, when the arterial waveform signal is accurate, MostCare and transpulmonary thermodilution systems exhibit good agreement even after the reduction of norepinephrine and changes in vascular tone or volume expansion. Thus, MostCare can be considered as a reliable and useful tool in emergency clinical settings where highly invasive devices are not promptly available.

Author Contributions: Conceptualization, P.P.; Data curation, P.P., I.V. and F.C.; Formal analysis, E.S.; Methodology, E.S.; Supervision, P.N.; Validation, A.D.C.; Writing—original draft, P.P.; Writingreview \& editing, I.V. and A.D.C. All authors have read and agreed to the published version of the manuscript.

Funding: No funding was received for this study.

Institutional Review Board Statement: Local ethic committee approval (Ethical Board protocol n ${ }^{\circ} 26658$ ).

Informed Consent Statement: Written informed consent or delayed consent was obtained from each patient or legal surrogate according to the Local Ethics Committee dispositions.

Data Availability Statement: Not applicable.

Conflicts of Interest: P.P. has received unrestricted educational support in the form of payment of conferences registration fees (ISICEM, Brussels, 2015, 2016) from Vygon-Vytech, the manufacturer of the MostCare device. He does not have any financial relationship with this nor other companies. The remaining authors have no conflict of interest to declare.

\section{References}

1. Payen, D.; Gayat, E. Which general intensive care unit patients can benefit from placement of the pulmonary artery catheter? Crit. Care 2006, 10, S7. [CrossRef] [PubMed]

2. Vincent, J.L.; Pinsky, M.R.; Sprung, C.L.; Levy, M.; Marini, J.J.; Payen, D.; Rhodes, A.; Takala, J. The pulmonary artery catheter: In medio virtus. Crit. Care Med. 2008, 36, 3093-3096. [CrossRef] [PubMed]

3. Connors, A.F.; Speroff, T.; Dawson, N.V.; Thomas, C.; Harrell, F.E.; Wagner, D.; Desbiens, N.; Goldman, L.; Wu, A.W.; Califf, R.M.; et al The Effectiveness of Right Heart Catheterization in the Initial Care of Critically Ill Patients. JAMA 1996, 276, 889-897. [CrossRef] [PubMed]

4. Sangkum, L.; Liu, G.L.; Yu, L.; Yan, H.; Kaye, A.D.; Liu, H. Minimally invasive or noninvasive cardiac output measurement: An update. J. Anesth. 2016, 30, 461-480. [CrossRef] 
5. Sakka, S.G.; Kozieras, J.; Thuemer, O.; Van Hout, N. Measurement of cardiac output: A comparison between transpulmonary thermodilution and uncalibrated pulse contour analysis. Br. J. Anaesth. 2007, 99, 337-342. [CrossRef]

6. Saraceni, E.; Rossi, S.; Persona, P.; Dan, M.; Rizzi, S.; Meroni, M.; Ori, C. Comparison of two methods for cardiac output measurement in critically ill patients. Br. J. Anaesth. 2011, 106, 690-694. [CrossRef]

7. Alhashemi, J.A.; Cecconi, M.; Hofer, C.K. Cardiac output monitoring: An integrative perspective. Crit. Care 2011, 15, 214-219. [CrossRef]

8. Goedje, O.; Hoeke, K.; Lichtwarck-Aschoff, M.; Faltchauser, A.; Lamm, P.; Reichart, B. Continuous cardiac output by femoral arterial thermodilution calibrated pulse contour analysis: Comparison with pulmonary arterial thermodilution. Crit. Care Med. 1999, 27, 2407-2412. [CrossRef]

9. Holm, C.; Melcer, B.; Hörbrand, F.; Von Donnersmarck, G.H.; Mühlbauer, W. Arterial thermodilution: An alternative to pulmonary artery catheter for cardiac output assessment in burn patients. Burns 2001, 27, 161-166. [CrossRef]

10. Huber, W.; Koenig, J.; Mair, S.; Schuster, T.; Saugel, B.; Eyer, F.; Phillip, V.; Schultheiss, C.; Thies, P.; Mayr, U.; et al. Predictors of the accuracy of pulse-contour cardiac index and suggestion of a cali-bration-index: A prospective evaluation and validation study. BMC Anesthesiol. 2015, 15, 45. [CrossRef]

11. Hamzaoui, O.; Monnet, X.; Richard, C.; Osman, D.; Chemla, D.; Teboul, J.-L. Effects of changes in vascular tone on the agreement between pulse contour and transpulmonary thermodilution cardiac output measurements within an up to 6-hour calibra-tion-free period. Crit. Care Med. 2008, 36, 434-440. [CrossRef] [PubMed]

12. Saugel, B.; Huber, W.; Nierhaus, A.; Kluge, S.; Reuter, D.A.; Wagner, J.Y. Advanced Hemodynamic Management in Patients with Septic Shock. BioMed Res. Int. 2016, 2016, 1-11. [CrossRef] [PubMed]

13. Cecconi, M.; De Backer, D.; Antonelli, M.; Beale, R.; Bakker, J.; Hofer, C.K.; Jaeschke, R.; Mebazaa, A.; Pinsky, M.R.; Teboul, J.L.; et al. Consensus on circulatory shock and hemodynamic monitoring. Task force of the European Society of Intensive Care Medicine. Intensiv. Care Med. 2014, 40, 1795-1815. [CrossRef] [PubMed]

14. Trof, R.J.; Beishuizen, A.; Cornet, A.D.; De Wit, R.J.; Girbes, A.R.J.; Groeneveld, A.B.J. Volume-limited versus pressure-limited hemodynamic management in septic and nonseptic shock. Crit. Care Med. 2012, 40, 1177-1185. [CrossRef]

15. Scolletta, S.; Romano, S.M.; Biagioli, B.; Capannini, G.; Giomarelli, P. Pressure recording analytical method (PRAM) for measurement of cardiac output during various hemodynamic states. Br. J. Anaesth. 2005, 95, 159-165. [CrossRef]

16. Franchi, F.; Silvestri, R.; Cubattoli, L.; Taccone, F.S.; Donadello, K.; Romano, S.M.; Giomarelli, P.; McBride, W.T.; Scolletta, S. Comparison between an uncalibrated pulse contour method and thermodilution technique for cardiac output estimation in septic patients. Br. J. Anaesth. 2011, 107, 202-208. [CrossRef]

17. Gopal, S.; Do, T.; Pooni, J.S.; Martinelli, G. Validation of cardiac output studies from the Mostcare compared to a pulmonary artery catheter in septic patients. Minerva Anestesiol. 2014, 80, 314-323.

18. Oren-Grinberg, A. The PiCCO Monitor. Int. Anesthesiol. Clin. 2010, 48, 57-85. [CrossRef]

19. Rhodes, A.A.; Evans, L.; Alhazzani, W.; Levy, M.M.; Antonelli, M.; Ferrer, R.; Kumar, A.; Sevransky, J.E.; Sprung, C.L.; Nunnally, M.E.; et al. Surviving Sepsis Campaign. Crit. Care Med. 2017, 45, 486-552. [CrossRef]

20. Romano, S.M.; Pistolesi, M. Assessment of cardiac output from systemic arterial pressure in humans. Crit. Care Med. 2002, 30, 1834-1841. [CrossRef]

21. Guyton, A.C.; Lindsey, A.W.; Kaufmann, B.N. Effect of Mean Circulatory Filling Pressure and Other Peripheral Circulatory Factors on Cardiac Output. Am. J. Physiol. Content 1955, 180, 463-468. [CrossRef] [PubMed]

22. Romagnoli, S.; Romano, S.M.; Bevilacqua, S.; Lazzeri, C.; Gensini, G.F.; Pratesi, C.; Quattrone, D.; Dini, D.; De Gaudio, A.R. Dynamic response of liquid-filled catheter systems for measurement of blood pressure: Precision of measurements and re-liability of the Pressure Recording Analytical Method with different disposable systems. J. Crit. Care 2011, 26, 415-422. [CrossRef] [PubMed]

23. Romagnoli, S.S.; Ricci, Z.; Quattrone, D.; Tofani, L.; Tujjar, O.; Villa, G.; Romano, S.M.; De Gaudio, A.R. Accuracy of invasive arterial pressure monitoring in cardiovascular patients: An observational study. Crit. Care 2014, 18, 1-11. [CrossRef] [PubMed]

24. Gardner, R.M. Direct Blood Pressure Measurement-Dynamic Response Requirements. J. Am. Soc. Anesthesiol. 1981, 54, 227-236. [CrossRef] [PubMed]

25. Hofkens, P.-J.; Verrijcken, A.; Merveille, K.; Neirynck, S.; Van Regenmortel, N.; De Laet, I.; Schoonheydt, K.; Dits, H.; Bein, B.; Huber, W.; et al. Common pitfalls and tips and tricks to get the most out of your transpulmonary thermodi-lution device: Results of a survey and state-of-the-art review. Anaesthesiol. Intensive Ther. 2015, 47, 89-116. [CrossRef]

26. Bland, J.M.; Altman, D.G. Statistical methods for assessing agreement between two methods of clinical measurement. Lancet 1986, 1,307-310. [CrossRef]

27. Critchley, L.A.H.; Critchley, J.A.J.H. A Meta-Analysis of Studies Using Bias and Precision Statistics to Compare Cardiac Output Measurement Techniques. J. Clin. Monit. Comput. 1999, 15, 85-91. [CrossRef]

28. Critchley, L.A.H.; Yang, X.X.; Lee, A. Assessment of Trending Ability of Cardiac Output Monitors by Polar Plot Methodology. J. Cardiothorac. Vasc. Anesth. 2011, 25, 536-546. [CrossRef]

29. Gust, R.; Gottschalk, A.; Bauer, H.; Böttiger, B.W.; Böhrer, H.; Martin, E. Cardiac output measurement by transpulmonary versus conventional thermodilution technique in intensive care patients after coronary artery bypass grafting. J. Cardiothorac. Vasc. Anesth. 1998, 12, 519-522. [CrossRef]

30. Tannenbaum, G.A.; Mathews, D.; Weissman, C. Pulse contour cardiac output in surgical intensive care unit patients. J. Clin. Anesth. 1993, 5, 471-478. [CrossRef] 
31. Rödig, G.; Prasser, C.; Keyl, C.; Liebold, A.; Hobbhahn, J. Continuous cardiac output measurement: Pulse contour analysis vs thermodilution technique in cardiac surgical patients. Br. J. Anaesth. 1999, 82, 525-530. [CrossRef] [PubMed]

32. Felbinger, T.W.; Reuter, D.A.; Eltzschig, H.K.; Bayerlein, J.; Goetz, A.E. Cardiac index measurements during rapid preload changes: A comparison of pulmonary artery thermodilution with arterial pulse contour analysis. J. Clin. Anesth. 2005, 17, 241-248. [CrossRef] [PubMed]

33. Jellema, W.T.; Wesseling, K.H.; Groeneveld, A.B.; Stoutenbeek, C.P.; Thijs, L.G.; van Lieshout, J.J. Continuous cardiac output in septic shock by simulating a model of the aortic input impedance: A comparison with bolus injection thermodilution. Anesthesiology 1999, 90, 1317-1328. [CrossRef] [PubMed]

34. Scolletta, S.; Franchi, F.; Romagnoli, S.; Carlà, R.; Donati, A.; Fabbri, L.P.; Forfori, F.; Alonso-Iñigo, J.M.; Laviola, S.; Mangani, V.; et al. Pulse wave analysis Cardiac Output validation (PulseCOval) Group. Comparison Between Doppler-Echocardiography and Uncalibrated Pulse Contour Method for Cardiac Output Measurement: A Multicenter Observational Study. Crit. Care Med. 2016, 44, 1370-1379. [CrossRef]

35. Alonso-Iñigo, J.M.; Escribá, F.J.; Carrasco, J.I.; Fas, M.J.; Argente, P.; Galvis, J.M.; Llopis, J.E. Measuring cardiac output in children undergoing cardiac catheterization: Comparison between the Fick method and PRAM (pressure recording analytical method). Pediatr. Anesth. 2016, 26, 1097-1105. [CrossRef]

36. Franchi, F.; Falciani, E.; Donadello, K.; Zacà, V.; Silvestri, R.; Taccone, F.S.; Cubattoli, L.; Mongelli, P.; Giomarelli, P.; Scolletta, S. Echocardiography and pulse contour analysis to assess cardiac output in trauma patients. Minerva Anestesiol. 2012, 79, 137-146.

37. Franchi, F.; Taccone, F.S.; Romagnoli, S.; Persona, P.; Donati, A. Pitfalls of hemodynamic monitoring techniques: Troubles in research or in clinical practice? Minerva Anestesiol. 2014, 81, 234-235.

38. García, M.M.; Romero, M.G.; Gil Cano, A.; Rhodes, A.; Grounds, R.M.; Cecconi, M. Impact of arterial load on the agreement between pulse pressure analysis and esophageal Doppler. Crit. Care 2013, 17, R113. [CrossRef]

39. Vincent, J.L.; Pelosi, P.; Pearse, R.; Payen, D.; Perel, A.; Hoeft, A.; Romagnoli, S.S.; Ranieri, V.M.; Ichai, C.; Forget, P.; et al. Perioperative cardiovascular monitoring of high-risk patients: A consensus of 12. Crit. Care 2015, 19, 1-12. [CrossRef]

40. Monnet, X.; Vaquer, S.; Anguel, N.; Jozwiak, M.; Cipriani, F.; Richard, C.; Teboul, J.-L. Comparison of pulse contour analysis by Pulsioflex and Vigileo to measure and track changes of cardiac output in critically ill patients. Br. J. Anaesth. 2015, 114, 235-243. [CrossRef] 